\title{
Adherence to a Dietary Approach to Stop Hypertension (DASH)-Style in Relation to Daytime Sleepiness
}

This article was published in the following Dove Press journal: Nature and Science of Sleep

\author{
Naseh Pahlavani $\mathbb{1}^{1, *}$ \\ Sayyed Saeid Khayyatzadeh ${ }^{2,3, *}$ \\ Vahideh Banazadeh' \\ Mohammad Bagherniya (iD) ${ }^{4}$ \\ Maryam Tayefi ${ }^{5}$ \\ Saeid Eslami $\mathbb{D D}^{6}$ \\ Gordon A Ferns ${ }^{7}$ \\ Majid Ghayour-Mobarhan $\mathbb{1 D}^{8,9}$
}

'Student Research Committee, Mashhad University of Medical Sciences, Mashhad, Iran; ${ }^{2}$ Nutrition and Food Security Research Center, Shahid Sadoughi University of Medical Sciences, Yazd, Iran; ${ }^{3}$ Department of Nutrition, Faculty of Health, Shahid Sadoughi University of Medical Sciences, Yazd, Iran; ${ }^{4}$ Department of Community Nutrition, School of Nutrition and Food Science, Food Security Research Center, Isfahan University of Medical Sciences, Isfahan, Iran; ${ }^{5}$ Department of Cardiovascular, Imam Reza Hospital, Mashhad University of Medical Science (MUMS), Mashhad, Iran; ${ }^{6}$ Department of Medical Informatics, Faculty of Medicine, Mashhad University of Medical Sciences, Mashhad, Iran; ${ }^{7}$ Division of Medical Education, Brighton and Sussex Medical School, Brighton, Sussex, BNI 9PH, UK; ${ }^{8}$ Department of Modern Sciences and Technologies, Faculty of Medicine, Mashhad University of Medical Sciences, Mashhad, Iran; ${ }^{9}$ Metabolic Syndrome Research Center, School of Medicine, Mashhad University of Medical Sciences, Mashhad, Iran

*These authors contributed equally to this work

Correspondence: Majid Ghayour-Mobarhan Tel +985 I 38002288

Fax +985I38002287

Email ghayourm@mums.ac.ir
Background: The beneficial impact of adherence to a DASH diet on several metabolic conditions and psychological well-being has been shown previously. Dietary modification can affect sleep quality. Thus, the aim of this present study was to investigate the correlation between adherence to the DASH diet and daytime sleepiness score in adolescent girls.

Methods: A total of 535 adolescent girls aged between 12 and 18 years old were recruited from different regions of Khorasan Razavi in northeastern of Iran, using a random cluster sampling method. DASH scores were determined according to the method of Fung et al. A Persian translation of the Epworth Sleepiness Scale (ESS-IR) was used to assess of daytime sleepiness. To investigate the correlation between DASHstyle diet and daytime sleepiness score, we applied logistic regression analysis in crude and adjusted models.

Results: As may be expected, participants with the greatest adherence to the DASH diet had significantly higher intakes of fruits, vegetables, low-fat dairy products, fish and nuts, and lower consumption of refined grains, red and processed meat, sugar-sweetened beverages and sweets. There was an inverse correlation between adherence to the DASH-style diet and scores for daytime sleepiness in crude model $(\beta=-0.12 ; \mathrm{P}=0.005)$. These findings were remained significant after adjustment for confounding variables $(\beta=-0.08 \mathrm{P}=0.04)$.

Conclusion: There is an inverse correlation between adherence to DASH diet and daytime sleepiness score. Further studies, particularly longitudinal studies, are required to determine whether dietary intervention may improve daytime sleepiness.

Keywords: DASH diet, sleep, adolescents, daytime functioning

\section{Introduction}

Sleep disorders and poor sleep quality influence health, life quality and productivity. ${ }^{1}$ Currently, one-third to one quarter of the people in developed countries report that they suffer from sleep disorders. ${ }^{2}$ Daytime sleepiness is a highly prevalent sleep problem that might lead to poor sleep quality, insufficient sleep, circadian rhythm disorders and insomnia., ${ }^{3,4}$ Several long-term adverse consequences are attributed to the poor quality and quantity of sleep and sleep disturbances including cardiovascular diseases, obesity, neuroendocrine and metabolic disorders, diabetes, hypertension and mental health problems such as affective disorder, cognitive impairment, fatigue, daytime sleepiness and depression, and this has an impact on work absenteeism. ${ }^{5-9}$ 
Adolescence is an important period for physical and psychological development, and optimal mental health during this time is essential for the health and well-being of adolescents. It is estimated that $20 \%$ of adolescents are affected by mental disorders. ${ }^{10}$

A good quality of nutritional intake is related to good mental health during adolescence, ${ }^{11}$ however there is evidence that the quality of diet in young people has declined in recent decades. ${ }^{12}$ Furthermore, dietary modification can directly affect sleep quality. ${ }^{13-15}$ The DASH dietary pattern is characterized by the consumption of a high intake of fruit and vegetables, protein and fiber, low-fat dairy products, whole grains, poultry, fish, and nuts, in addition to sufficient amounts of other nutrient-rich foods containing minerals known to have an effects on lowering blood pressure, including potassium, magnesium and calcium. ${ }^{16,17}$ A DASH diet appears to have a beneficial effect on hypertension, and several other conditions including the presence of obesity, metabolic syndrome, gestational diabetes, type 2 diabetes, stroke, and cardiovascular disease. ${ }^{18}$ Furthermore, metabolic conditions such as overweight and obesity are significant risk factors for impaired sleep and insomnia. ${ }^{19}$ The DASH diet also has beneficial effects on psychological disorders such as depression. ${ }^{18} \mathrm{We}$ hypothesized that adherence to DASH-style diet might have potential benefits for daytime sleepiness.

To the best of our knowledge, there are no previous studies that have investigated the relationship between adherences to a DASH diet and sleep disorders. In this study, we have investigated the correlation between adherence to the DASH diet and the daytime sleepiness in adolescent girls residing in the cities of Mashhad and Sabzevar, in northeastern Iran.

\section{Method and Material Study Population}

In this cross-sectional study that started in January 2015, initially, 1026 individuals were invited to participate in the study, and finally 535 adolescent girls were selected and recruited using a random cluster sampling method from several schools in different areas of Khorasan Razavi region, of northeastern Iran to participate in the study. Students who were between 12 and 18 years of age and had no history of chronic diseases (colitis, diabetes, cardiovascular diseases, cancer and hepatitis) were included in our study. All of the subjects and their parents were asked to provide written informed consent before the beginning of the study. This study done according to the guidelines of the Helsinki Declaration and all procedures involving human patients were approved by the Ethics Committee of Mashhad University of Medical Sciences (Code: 931188) and supported by the Department of Nutrition, Faculty of Medicine of this University.

\section{Demographic and Anthropometric}

\section{Assessment}

Demographic data including age, parent death, parent divorce, passive smoking (the presence of a smoker in their household), menstruation (yes or no), medical history, dietary supplements or drug use was collected by an experienced interviewer. Physical activity information was obtained by using the validated Modifiable Activity Questionnaire (MAQ). ${ }^{20}$ Physical activity level was calculated based on metabolic equivalent task (MET) hour per day. In addition, a validated Persian version of the Beck Depression Inventory (BDI) was used for the assessment of depression in the current study. Anthropometric variables include weight, height and body mass index (BMI) were obtained using standard protocol.

\section{Assessment of Sleep Disorders}

A Persian translation of the Epworth Sleepiness Scale (ESS-IR) was used for the assessment of daytime sleepiness, ${ }^{21}$ and its reliability and validity has been published previously. ${ }^{22}$ This questionnaire asks respondents to rate their sleepiness in eight daily situations from 0 to 3 giving a total score of 0 (no daytime sleepiness) to 24 (the most excessive daytime sleepiness).

\section{Dietary Assessment}

A food frequency questionnaire (FFQ) containing questions about 147 food items was used to obtained dietary intake data. ${ }^{23}$ The assessment of the validity and reliability of this has been previously reported. ${ }^{23,24}$ The questionnaire was completed by face-to-face interview. To estimate energy and nutrient intakes, the reported portion size in FFQ were converted to grams using household measures and then were entered to the Nutritionist 4 software Nutritionist IV software. ${ }^{25}$ The effect of energy intake was normalized by calculating the food group intakes per $1000 \mathrm{Kcal}$.

\section{Adherence to DASH-Style Diet}

DASH scores were determined using the method of Fung et al. $^{26}$ DASH scores were based on foods and nutrients emphasized or minimized in the DASH diet, 
focusing on eight components: high intake of fruits, vegetables, nuts and legumes, dairy products, and low intake of grains, sugar-sweetened beverages and sweets, sodium, and red and processed meats according to quintile categories (ie, lowest quintile is considered 1 point and highest quintile is considered 5 points). Participants with lower quintile of intake of sweetened beverages, sodium, and red and processed meats were assigned higher points (ie, the highest quintile received a score of 5 and the lowest quintile received a score of 1). Finally, all component scores were integrated to obtain the overall DASH score, ranging from 8 to 40 points.

\section{Statistical Methods}

Participants were categorized into four groups based on quartiles of their DASH-style dietary scores. To compare the demographic characteristics of the study population, one-way-ANOVA and chi-squared analyses were applied across quartiles of DASH score for continuous (age, physical activity, depression score) and categorical variables (passive smoking, menstruation, parent death, parent divorce and BMI percentiles), respectively. Energy-adjusted dietary intakes of study participants were compared by linear regression across quartiles of DASH score. Univariate and multivariate regression was conducted in crude and adjusted models to examine the correlation between adherence to DASH-style diets and scores of daytime sleepiness. In the adjusted models, we adjusted for age and energy intake in Model I. Additionally, adjustment was done for physical activity and BMI in Model II. All statistical analyses were performed using the SPSS v 15.0 (SPSS Corp, version 15, Chicago, IL, USA). P-values less than 0.05 were defined as being statistically significant.

\section{Results \\ General Characteristics of Study Population}

General characteristics of the study participants across quartile categories of DASH score are shown in Table 1. There were no significant differences in physical activity, passive smoking, menstruation status, parent death, parent divorce and BMI percentiles of the study participants between the quartiles of DASH score. However, individuals with higher DASH scores were significantly younger than the fourth quartile $(14.1 \pm 1.6$ in 1 st year vs 14.8 \pm 1.5 year in 4 th; $p=0.005)$. The subjects with lower
DASH scores were more likely to have a high depression score $(11.6 \pm 8.1$ in 1 st vs $8.6 \pm 7.1$ in 4 th; $p=0.005)$.

As shown in Table 2, the participants with a greater adherence to the DASH-style diet had a higher intake of fruits, vegetables, low-fat dairy products, fish, nuts, legumes and seeds $(p<0.001)$. Consumption of refined grains, red and processed meat, sugar-sweetened beverages (SSB), sweets and spices were significantly higher among the subjects within the 4 th quartile of DASH diet category compared to the 1 st quartile $(p<0.01)$. In addition, intakes of energy, carbohydrate, protein, dietary fiber, vitamin $\mathrm{C}$, vitamin $\mathrm{D}$, vitamin $\mathrm{A}$, calcium, magnesium, potassium, and folate were significantly higher among individuals who were categorized in the 4th quartile of DASH diet in comparison to the 1 st quartile $(\mathrm{p}<0.05)$. The subjects in the 1st quartile of DASH diet consumed higher amounts of total fat and sodium compared with 4th quartile $(\mathrm{p}<0.001)$.

The correlations between the compliance with a DASH-diet style and daytime sleepiness is shown in Table 3. There was an inverse correlation between adherence to the DASH-style diet and daytime sleepiness score in unadjusted model $(\beta=-0.12 ; \mathrm{P}$ value $=0.005)$. Likewise, this inverse relationship was significant after adjustment for confounding factors in Model I $(\beta=$ $-0.12 ; \mathrm{P}=0.005)$, Model II $(\beta=-0.08 ; \mathrm{P}$ value $=0.04)$, Model III $(\beta=-0.08 ; \mathrm{P}=0.04)$.

\section{Discussion}

EDS is a common complaint, which is described as the tendency to fall asleep during the day when subject means to remain awake. ${ }^{27}$ Deleterious outcomes of EDS include physical and mental disorders that limit subject's function and quality of life. ${ }^{28}$ In addition, irregular sleep patterns can have adverse long-term clinical conditions which may be associated with disability and mortality. ${ }^{29}$ The prevalence of EDS is increased in the adolescent period due to hormonal changes-related to puberty and environmental factors. ${ }^{30}$ With regard to important consequence of sleep health on quality of life, it is necessary to identify major factors, which may be effective on management or treatment of sleep-related disorders.

We have found that a high adherence to a DASH-style diet is associated with less daytime sleepiness in adolescent girls. After adjustment for confounding variables, an inverse correlation was observed between a greater adherence to the DASH-style diet and lower scores for daytime sleepiness. To the best of our knowledge, this report is the 
first study that investigated the correlation between adherence to the DASH-dietary pattern and sleep disorders in adolescents. The prevalence of depression is estimated as at least twofold in adolescent girls in comparison to other age and sex groups and hence these individuals are a vulnerable group for psychological disorders development. ${ }^{31,32}$

In one cross-sectional study conducted in women with young children, although short duration of sleep was not associated with quality of diet; a long duration of sleep was related to a lower quality of diet. $^{33}$ We have previously shown that following DASH diet reduces insomnia in adolescents. ${ }^{34}$ However, in another study conducted among young women, it has been shown that short sleep duration was significantly associated with low quality of diet. $^{35}$ Another study found that following a diet with low inflammatory index (such as DASH diet) improved sleep quality. $^{36}$

Dietary modification may be a practical approach to preventing sleep disorders. In line with our results, in a previous study, it has been found that a sodium-

Table I Descriptive Characteristics of Study Participants by Quartiles of DASH-Diet Style

\begin{tabular}{|c|c|c|c|c|c|c|}
\hline & & \multicolumn{5}{|c|}{$\begin{array}{l}\text { Quartiles of DASH Score (Ranged } \\
\text { from } 8 \text { to } 40 \text { ) }\end{array}$} \\
\hline & & QI & Q2 & Q3 & Q4 & $\begin{array}{l}P \text { for } \\
\text { Trend* }\end{array}$ \\
\hline \multicolumn{2}{|l|}{ Age $(y)$} & $\begin{array}{r}14.8 \\
\pm 1.5\end{array}$ & $\begin{array}{r}14.7 \\
\pm 1.5\end{array}$ & $\begin{array}{r}14.4 \\
\pm 1.5\end{array}$ & $\begin{array}{l}14.1 \\
\pm 1.6\end{array}$ & 0.005 \\
\hline \multicolumn{2}{|c|}{$\begin{array}{l}\text { Physical activity (MET. } \\
\text { h/day) }\end{array}$} & $\begin{array}{l}6.4 \\
\pm 0.51\end{array}$ & $\begin{array}{l}6.4 \\
\pm 0.38\end{array}$ & $\begin{array}{l}6.4 \\
\pm 0.52\end{array}$ & $\begin{array}{l}6.4 \\
\pm 0.51\end{array}$ & 0.89 \\
\hline \multicolumn{2}{|c|}{ Passive smoker (\%) } & 26.4 & 20.9 & 23.5 & 15.5 & 0.23 \\
\hline \multicolumn{2}{|c|}{ Menstruation (\%) } & 90.5 & 90.7 & 86.9 & 81 & 0.2 \\
\hline \multirow{3}{*}{$\begin{array}{l}\text { BMI } \\
\text { percentile } \\
(\%)\end{array}$} & $<3$ & 3.4 & 2.4 & 0.8 & 1.1 & \multirow[t]{3}{*}{0.37} \\
\hline & $\begin{array}{l}3-85 \\
85-95\end{array}$ & $\begin{array}{l}82.2 \\
9.6\end{array}$ & $\begin{array}{l}80 \\
10.4\end{array}$ & $\begin{array}{l}79.9 \\
9.7\end{array}$ & $\begin{array}{l}72.4 \\
17.2\end{array}$ & \\
\hline & $>95$ & 4.8 & 7.2 & 9.6 & 9.3 & \\
\hline \multicolumn{2}{|c|}{ Depression score } & $\begin{array}{l}11.6 \\
\pm 8.1\end{array}$ & $\begin{array}{r}10.7 \\
\pm 7.8\end{array}$ & $\begin{array}{l}9.4 \\
\pm 7.3\end{array}$ & $\begin{array}{l}8.6 \\
\pm 7.1\end{array}$ & 0.01 \\
\hline \multicolumn{2}{|c|}{ Parent death (\%) } & 5.1 & 3.6 & 3.6 & 4 & 0.99 \\
\hline \multicolumn{2}{|c|}{ Parent divorce (\%) } & 7 & 5.7 & 3.6 & 3 & 0.81 \\
\hline
\end{tabular}

Note: *One-way ANOVA and chi-squared analyses were used to test the trend of continuous and categorical variables, respectively, across the quartiles of DASH score. restricted diet (maximum intake of $3 \mathrm{~g}$ of sodium per day) for one week improved the symptoms of obstructive sleep apnea compared with control group. ${ }^{37}$ Similarly, Kasai et al showed that a high sodium intake plays an important role in the pathogenesis of sleep apnea. ${ }^{38}$

It has been hypothesized that free radicals may accumulate in the cerebral tissues during wakefulness, are removed during sleep, and that sleep deprivation can, therefore, lead to increased cerebral oxidative stress. ${ }^{39}$ Obstructive sleep apnea syndrome is associated with an increase in oxidative stress that is produced by recurrent episodes of ischemia-reperfusion. ${ }^{40}$ However, several studies have also linked oxidative stress with insomnia. In one study conducted on individuals with primary insomnia significantly lower selenium-containing antioxidant enzyme activity (GSH-Px) and higher serum malondialdehyde (MDA) levels were found compared with control group. ${ }^{41}$ It has also been shown that a DASH diet could reduce the rate of oxidative stress, ${ }^{42}$ which may also support the importance of our findings, following DASH diet to prevent daytime sleepiness. Additionally, DASH diet has been associated with inflammation, ${ }^{43}$ which in turn is associated with scarce sleep medicine, ${ }^{44}$ Up to date, only one study investigated the correlation between inflammatory potential of the diet and sleep, and showed that individuals adherent to a proinflammatory diet report worse sleep quality. ${ }^{36}$

Studies have shown that weight disorders such as overweight and obesity are usually associated with sleep problems, ${ }^{45}$ and some studies have shown that adherence to DASH diet has helped to correct this trend; ${ }^{46,47}$ therefore, it is expected that adherence to DASH diet can improve some sleep disorders such as insomnia. Interestingly, obesity has been demonstrated to be a modifying factor of the correlation between higher adherences to the Mediterranean diet and sleep features. In particular, it has been shown that correlation between higher adherence to Mediterranean diet and sleep quality is only significant in normal-weight individuals. ${ }^{48}$

In our study, individuals in a 4th quartile of adherence to DASH-style diet consumed more protein and carbohydrate than subjects in the 1st quartile. It has been previously shown that individuals with a normal sleep pattern reported consuming more protein compared to individuals with insomnia. ${ }^{49}$ Tanaka et al have shown that a low protein intake was associated with difficulty initiating sleep (DIS), and poor quality of sleep (PQS), while low carbohydrate intake was also associated with difficulty maintaining sleep 
Table 2 Food and Nutrient Intakes of Adolescents According to Quartiles of DASH-Type Diet

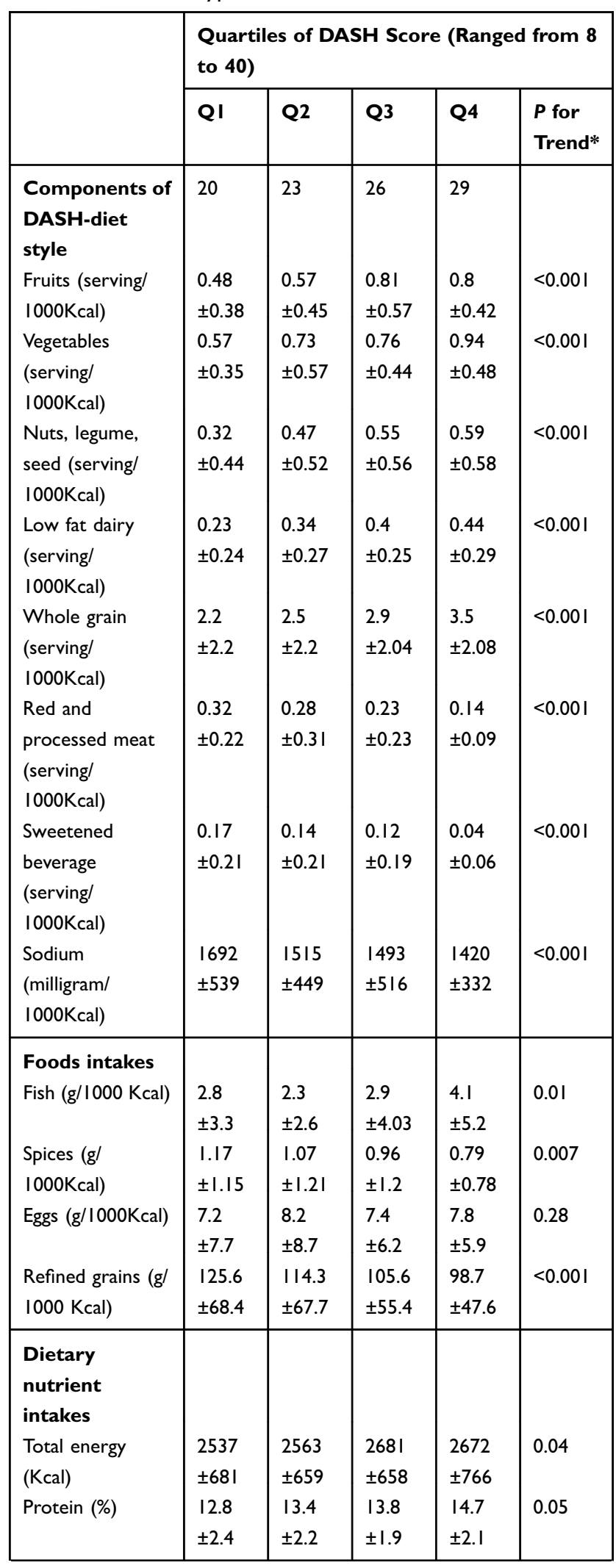

(Continued)
Table 2 (Continued).

\begin{tabular}{|c|c|c|c|c|c|}
\hline & \multicolumn{5}{|c|}{$\begin{array}{l}\text { Quartiles of DASH Score (Ranged from } 8 \\
\text { to } 40 \text { ) }\end{array}$} \\
\hline & QI & Q2 & Q3 & Q4 & $\begin{array}{l}P \text { for } \\
\text { Trend* }\end{array}$ \\
\hline Carbohydrate (\%) & $\begin{array}{l}52.7 \\
\pm 7.9\end{array}$ & $\begin{array}{l}54.3 \\
\pm 7.6\end{array}$ & $\begin{array}{l}55.5 \\
\pm 6.7\end{array}$ & $57 \pm 6.7$ & 0.04 \\
\hline Total fat (\%) & $\begin{array}{l}36.2 \\
\pm 8.8\end{array}$ & $34.3 \pm 8$ & $33 \pm 6.6$ & $3 I \pm 7$ & $<0.001$ \\
\hline $\begin{array}{l}\text { Sucrose }(g / \\
\text { I000Kcal) }\end{array}$ & $\begin{array}{l}8.5 \\
\pm 5.6\end{array}$ & $\begin{array}{l}9.08 \\
\pm 6.4\end{array}$ & $\begin{array}{l}8.3 \\
\pm 4.1\end{array}$ & $\begin{array}{l}7.9 \\
\pm 4.9\end{array}$ & 0.22 \\
\hline $\begin{array}{l}\text { Dietary fiber ( } g / \\
1000 \text { Kcal) }\end{array}$ & $\begin{array}{l}15.8 \\
\pm 6.4\end{array}$ & $\begin{array}{l}16.7 \\
\pm 6.5\end{array}$ & $\begin{array}{l}16.2 \\
\pm 5.1\end{array}$ & $\begin{array}{l}18.2 \\
\pm 5.2\end{array}$ & 0.009 \\
\hline $\begin{array}{l}\text { Vitamin C (mg/ } \\
1000 \mathrm{Kcal})\end{array}$ & $\begin{array}{l}28.7 \\
\pm 14.4\end{array}$ & $\begin{array}{l}34.3 \\
\pm 22.6\end{array}$ & $\begin{array}{l}40.2 \\
\pm 23.6\end{array}$ & $\begin{array}{l}41.6 \\
\pm 23.5\end{array}$ & $<0.001$ \\
\hline $\begin{array}{l}\text { Folate }(\mathrm{mcg} / \\
1000 \mathrm{Kcal})\end{array}$ & $\begin{array}{l}221.3 \\
\pm 48.3\end{array}$ & $\begin{array}{l}229.9 \\
\pm 53.9\end{array}$ & $\begin{array}{l}225.6 \\
\pm 42.7\end{array}$ & $\begin{array}{l}244.6 \\
\pm 48.3\end{array}$ & 0.002 \\
\hline $\begin{array}{l}\text { Vitamin A (mcg/ } \\
\text { I000Kcal) }\end{array}$ & $\begin{array}{l}184.5 \\
\pm 84.5\end{array}$ & $\begin{array}{l}213.1 \\
\pm \mid 20.1\end{array}$ & $\begin{array}{l}220.5 \\
\pm 95.7\end{array}$ & $\begin{array}{l}258.1 \\
\pm 119.1\end{array}$ & $<0.001$ \\
\hline $\begin{array}{l}\text { Vitamin D (mcg/ } \\
\text { l000Kcal) }\end{array}$ & $\begin{array}{l}0.74 \\
\pm 0.63\end{array}$ & $\begin{array}{l}0.82 \\
\pm 0.67\end{array}$ & $\begin{array}{l}0.83 \\
\pm 0.51\end{array}$ & $\begin{array}{l}1.06 \\
\pm 0.77\end{array}$ & $<0.001$ \\
\hline $\begin{array}{l}\text { Potassium (mg/ } \\
\text { l000Kcal) }\end{array}$ & $\begin{array}{l}1242 \\
\pm 242\end{array}$ & $\begin{array}{l}1362 \\
\pm 273\end{array}$ & $\begin{array}{l}1439 \\
\pm 265\end{array}$ & $\begin{array}{l}1539 \\
\pm 252.5\end{array}$ & $<0.001$ \\
\hline $\begin{array}{l}\text { Calcium (mg/ } \\
\text { I000Kcal) }\end{array}$ & $\begin{array}{l}380.3 \\
\pm 130.1\end{array}$ & $\begin{array}{l}428.6 \\
\pm 141.9\end{array}$ & $\begin{array}{l}453.6 \\
\pm 125.5\end{array}$ & $\begin{array}{l}477.6 \\
\pm 141.5\end{array}$ & $<0.001$ \\
\hline $\begin{array}{l}\text { Magnesium (mg/ } \\
\text { I000Kcal) }\end{array}$ & $\begin{array}{r}158.7 \\
\pm 39.6\end{array}$ & $\begin{array}{r}177.3 \\
\pm 36.3\end{array}$ & $\begin{array}{r}191.4 \\
\pm 34.8\end{array}$ & $\begin{array}{l}211.9 \\
\pm 34.4\end{array}$ & $<0.001$ \\
\hline
\end{tabular}

Notes: Data reported as mean \pm SD; * Linear regression was used to test the trend of continuous variables according to quartile.

(DMS) $)^{50}$ Altogether, these findings indicate that following DASH style diet parallel to intake high amounts of protein and carbohydrate might prevent sleep disorders.

We found that individuals with a greater adherence to a DASH-style diet consumed lower amounts of sweetened beverages and fat, and had fewer sleep disturbances. To explain these findings, it should be mentioned that the quality of diet plays an important

Table 3 Linear Regression Analysis of the Correlations Between DASH-Diet Style and Daytime Sleepiness

\begin{tabular}{|l|l|l|}
\hline \multicolumn{2}{|l|}{$\boldsymbol{\beta}$} & P-value \\
\hline \multicolumn{2}{|l|}{ Daytime sleepiness score } \\
\hline Crude & -0.12 & 0.005 \\
Model I & -0.11 & 0.01 \\
Model II & -0.08 & 0.04 \\
\hline
\end{tabular}

Notes: Model I, Adjusted for age, energy intake; Model II, Additionally adjusted for physical activity and BMI. 
role in determining the production of monoamines such as serotonin and dopamine that can influence receptor sensitivity and neurotransmitter transporters. Indeed, the correlation between serotonin levels and duration of sleep demonstrated in previous studies. ${ }^{51,52}$ In an animal study, it has been reported that long-term consumption of sugar had negatively influenced brain serotonin (5-hydroxytryptophan (5-HT1A)) receptor sensitivity. ${ }^{53}$ Findings of another study conducted in Wistar rats indicated that one week following a high fat, low carbohydrate diet there was a reduction in serotonin release in the hypothalamus. ${ }^{54}$ Thus, it seems that a diet with low amounts of sweetened beverages and fat might be effective in reducing sleep disorders.

The current study has some strength. To the best of our knowledge, it is the first study, which has investigated the relationship between adherence to DASH-style diet and daytime sleepiness. Also, it must be kept in mind that the acceptable sample size of girl adolescents and careful assessment of confounding is strengths of our study. Nevertheless, there are some limitations in our study that should be considered. Firstly, the present study is a crosssectional study and the temporality of relationships cannot be confirmed. Secondly, we used the FFQ for evaluating dietary intakes; misclassification is another limitation in our study, as is in any epidemiologic study. Thirdly, Daytime sleepiness was assessed by self-reported questionnaires and are probable to be susceptible to misreporting.

\section{Conclusion}

We found an inverse correlation between adherences to DASH diet and daytime sleepiness among adolescent girls. It seems that following a healthy diet pattern may have a beneficial effect on quality and duration of sleep. Further studies, particularly longitudinal studies are required to confirm these findings among larger population and whether intervention by dietary change is a practical solution.

\section{Acknowledgments}

The authors are grateful to all study participants, volunteers, and study personnel.

\section{Author Contributions}

All authors made substantial contributions to conception and design, acquisition of data, or analysis and interpretation of data; took part in drafting the article or revising it critically for important intellectual content; gave final approval of the version to be published; and agree to be accountable for all aspects of the work.

\section{Ethical Approval}

All procedures performed in studies involving human participants were in accordance with the ethical standards of the institutional and/or national research committee and with the 1964 Helsinki declaration and its later amendments or comparable ethical standards and Informed consent was obtained from all individual participants included in the study.

\section{Funding}

This study was funded by Mashhad and Sabzevar University of Medical Sciences (Grant Number: 931188).

\section{Disclosure}

The authors declared that have no conflict of interest.

\section{References}

1. Matuszek Ż, Kondrakiewicz K, Borzymowska Z, et al. Sleep disorders among students at Warsaw universities.

2. Pigeon WR. Diagnosis, prevalence, pathways, consequences \& treatment of insomnia. Indian J Med Res. 2010;131:321.

3. Jaussent I, Morin CM, Ivers H, Dauvilliers Y. Incidence, worsening and risk factors of daytime sleepiness in a population-based 5-year longitudinal study. Sci Rep. 2017;7:1372. doi:10.1038/s41598-01701547-0

4. Kaur G, Singh A. Excessive daytime sleepiness and its pattern among Indian college students. Sleep Med. 2017;29:23-28. doi:10.1016/j. sleep.2016.08.020

5. Fortier-Brochu É, Beaulieu-Bonneau S, Ivers H, Morin CM. Insomnia and daytime cognitive performance: a meta-analysis. Sleep Med Rev. 2012;16:83-94. doi:10.1016/j.smrv.2011.03.008

6. Kessler RC, Berglund PA, Coulouvrat C, et al. Insomnia and the performance of US workers: results from the America insomnia survey. Sleep. 2011;34:1161-1171. doi:10.5665/SLEEP.1230

7. Khazaie H, Chehri A, Sadeghi K, Heydarpour F, Soleimani A, Rezaei Z. Sleep hygiene pattern and behaviors and related factors among general population in West of Iran. Glob J Health Sci. 2016;8:114. doi:10.5539/gjhs.v8n8p114

8. Kucharczyk ER, Morgan K, Hall AP. The occupational impact of sleep quality and insomnia symptoms. Sleep Med Rev. 2012;16:547-559. doi:10.1016/j.smrv.2012.01.005

9. Quercioli A, Mach F, Montecucco F. Inflammation accelerates atherosclerotic processes in obstructive sleep apnea syndrome (OSAS). Sleep Breath. 2010;14:261-269. doi:10.1007/s11325-010-0338-3

10. UNICEF. Progress for Children: A Report Card for Adolescents. Vol. 10. New York, NY: UNICEF Division of Communication; 2012.

11. O'Neil A, Quirk SE, Housden S, et al. Relationship between diet and mental health in children and adolescents: a systematic review. $\mathrm{Am}$ J Public Health. 2014;104:e31-e42. doi:10.2105/AJPH.2014.302110

12. Wang Z-H, Zhai F-Y, Du S-F, Popkin B. Dynamic shifts in Chinese eating behaviors. Asia Pac J Clin Nutr. 2008;17:123-130. 
13. Afaghi A, O'connor H, Chow CM. High-glycemic-index carbohydrate meals shorten sleep onset. Am J Clin Nutr. 2007;85:426-430. doi:10.1093/ajen/85.2.426

14. Perron IJ, Pack AI, Veasey S. Diet/energy balance affect sleep and wakefulness independent of body weight. Sleep. 2015;38:1893-1903. doi:10.5665/sleep.5236

15. St-Onge M-P, Roberts A, Shechter A, Choudhury AR. Fiber and saturated fat are associated with sleep arousals and slow wave sleep. J Clin Sleep Med. 2016;12:19.

16. Elmer PJ, Obarzanek E, Vollmer WM, et al. Effects of comprehensive lifestyle modification on diet, weight, physical fitness, and blood pressure control: 18-month results of a randomized trial. Ann Intern Med. 2006;144:485-495. doi:10.7326/0003-4819-144-7-20060404000007

17. Rifai L, Pisano C, Hayden J, Sulo S, Silver MA. Impact of the DASH diet on endothelial function, exercise capacity, and quality of life in patients with heart failure. In: Baylor University Medical Center Proceedings. Vol. 28. Taylor \& Francis; 2015:151.

18. Valipour G, Esmaillzadeh A, Azadbakht L, Afshar H, Hassanzadeh A, Adibi P. Adherence to the DASH diet in relation to psychological profile of Iranian adults. Eur J Nutr. 2017;56:309-320. doi:10.1007/s00394-015-1081-0

19. Palm A, Janson C, Lindberg E. The impact of obesity and weight gain on development of sleep problems in a population-based sample. Sleep Med. 2015;16:593-597. doi:10.1016/j.sleep.2015.01.016

20. Delshad M, Ghanbarian A, Ghaleh NR, Amirshekari G, Askari S, Azizi F. Reliability and validity of the modifiable activity questionnaire for an Iranian urban adolescent population. Int J Prev Med. 2015;6:3. doi:10.4103/2008-7802.151433

21. Johns MW. A new method for measuring daytime sleepiness: the Epworth sleepiness scale. Sleep. 1991;14:540-545. doi:10.1093/ sleep/14.6.540

22. Sadeghniiat Haghighi K, Montazeri A, Khajeh Mehrizi A, et al. The Epworth sleepiness scale: translation and validation study of the Iranian version. Sleep Breath. 2013;17:419-426. doi:10.1007/ s11325-012-0646-x

23. Esfahani FH, Asghari G, Mirmiran P, Azizi F. Reproducibility and relative validity of food group intake in a food frequency questionnaire developed for the tehran lipid and glucose study. J Epidemiol. 2010;20:150-158. doi:10.2188/jea.JE20090083

24. Asghari G, Rezazadeh A, Hosseini-Esfahani F, Mehrabi Y, Mirmiran P, Azizi F. Reliability, comparative validity and stability of dietary patterns derived from an FFQ in the Tehran Lipid and Glucose Study. Br J Nutr. 2012;108:1109-1117. doi:10.1017/ S0007114511006313

25. Hord NG, Tang Y, Bryan NS. Food sources of nitrates and nitrites: the physiologic context for potential health benefits. Am J Clin Nutr. 2009;90:1-10. doi:10.3945/ajen.2008.27131

26. Fung TT, Chiuve SE, McCullough ML, Rexrode KM, Logroscino G, $\mathrm{Hu}$ FB. Adherence to a DASH-style diet and risk of coronary heart disease and stroke in women. Arch Intern Med. 2008;168:713-720. doi:10.1001/archinte.168.7.713

27. MW Johns, B Hocking. What is excessive daytime sleepiness. Sleep deprivation: causes, effects and treatment. Nova Science Publishers; 2009. Disponible en: http://www mwjohns com/wp-content/uploads/ 2008/09/johns-2009-what-iseds pdf.

28. Gaina A, Sekine M, Hamanishi S, et al. Daytime sleepiness and associated factors in Japanese school children. J Pediatr. 2007;151 (5):518-522.e4. doi:10.1016/j.jpeds.2007.04.036

29. Ohayon MM. Determining the level of sleepiness in the American population and its correlates. J Psychiatr Res. 2012;46:422-427. doi:10.1016/j.jpsychires.2011.06.008

30. Fallone G, Owens JA, Deane J. Sleepiness in children and adolescents: clinical implications. Sleep Med Rev. 2002;6:287-306. doi:10.1053/smrv.2001.0192
31. Kuehner C. Why is depression more common among women than among men? Lancet Psychiatry. 2017;4:146-158. doi:10.1016/ S2215-0366(16)30263-2

32. Pearson C, Janz T, Ali J. Mental and Substance Use Disorders in Canada. Ottawa, ON: Statistics Canada; 2013.

33. Xiao RS, Moore Simas TA, Pagoto SL, Person SD, Rosal MC, Waring ME. Sleep duration and diet quality among women within 5 years of childbirth in the United States: a cross-sectional study. Matern Child Health J. 2016;20:1869-1877. doi:10.1007/s10995016-1991-3

34. Rostami H, Khayyatzadeh SS, Tavakoli H, et al. The relationship between adherence to a dietary approach to stop hypertension (DASH) dietary pattern and insomnia. BMC Psychiatry. 2019;19:234. doi:10.1186/s12888-019-2220-6

35. Haghighatdoost F, Karimi G, Esmaillzadeh A, Azadbakht L. Sleep deprivation is associated with lower diet quality indices and higher rate of general and central obesity among young female students in Iran. Nutrition. 2012;28:1146-1150. doi:10.1016/j.nut.2012.04.015

36. Godos J, Ferri R, Caraci F, et al. Dietary inflammatory index and sleep quality in Southern Italian adults. Nutrients. 2019;11:1324. doi:10.3390/nu11061324

37. Fiori CZ, Martinez D, Gonçalves SC, Montanari CC, Fuchs FD. Effect of diuretics and sodium-restricted diet on sleep apnea severity: study protocol for a randomized controlled trial. Trials. 2015;16:188. doi:10.1186/s13063-015-0699-9

38. Kasai T, Arcand J, Allard JP, et al. Relationship between sodium intake and sleep apnea in patients with heart failure. $\mathrm{J} \mathrm{Am} \mathrm{Coll}$ Cardiol. 2011;58:1970-1974. doi:10.1016/j.jacc.2011.08.012

39. Reimund E. The free radical flux theory of sleep. Med Hypotheses. 1994;43:231-233. doi:10.1016/0306-9877(94)90071-X

40. Kent BD, Ryan S, McNicholas WT. Obstructive sleep apnea and inflammation: relationship to cardiovascular co-morbidity. Respir Physiol Neurobiol. 2011;178:475-481. doi:10.1016/j. resp.2011.03.015

41. Gulec M, Ozkol H, Selvi Y, et al. Oxidative stress in patients with primary insomnia. Prog Neuropsychopharmacol Biol Psychiatry. 2012;37:247-251. doi:10.1016/j.pnpbp.2012.02.011

42. Asemi Z, Samimi M, Tabassi Z, Sabihi S-S, Esmaillzadeh A. A randomized controlled clinical trial investigating the effect of DASH diet on insulin resistance, inflammation, and oxidative stress in gestational diabetes. Nutrition. 2013;29:619-624. doi:10.1016/j. nut.2012.11.020

43. Soltani S, Chitsazi MJ, Salehi-Abargouei A. The effect of dietary approaches to stop hypertension (DASH) on serum inflammatory markers: a systematic review and meta-analysis of randomized trials. Clin Nutr. 2018;37:542-550. doi:10.1016/j.clnu.2017.02.018

44. Irwin MR, Olmstead R, Carroll JE. Sleep disturbance, sleep duration, and inflammation: a systematic review and meta-analysis of cohort studies and experimental sleep deprivation. Biol Psychiatry. 2016;80:40-52. doi:10.1016/j.biopsych.2015.05.014

45. Singareddy R, Vgontzas AN, Fernandez-Mendoza J, et al. Risk factors for incident chronic insomnia: a general population prospective study. Sleep Med. 2012;13:346-353. doi:10.1016/j.sleep.20 11.10 .033

46. Blumenthal JA, Babyak MA, Hinderliter A, et al. Effects of the DASH diet alone and in combination with exercise and weight loss on blood pressure and cardiovascular biomarkers in men and women with high blood pressure: the ENCORE study. Arch Intern Med. 2010;170:126-135. doi:10.1001/archinternmed.2009.470

47. Shenoy SF, Poston WS, Reeves RS, et al. Weight loss in individuals with metabolic syndrome given DASH diet counseling when provided a low sodium vegetable juice: a randomized controlled trial. Nutr J. 2010;9:8. doi:10.1186/1475-2891-9-8

48. Grosso G, Mistretta A, Marventano S, et al. Beneficial effects of the Mediterranean diet on metabolic syndrome. Curr Pharm Des. 2014;20:5039-5044. doi:10.2174/1381612819666131206112144 
49. Zadeh SS, Begum K. Comparison of nutrient intake by sleep status in selected adults in Mysore, India. Nutr Res Pract. 2011;5:230-235. doi:10.4162/nrp.2011.5.3.230

50. Tanaka E, Yatsuya H, Uemura M, et al. Associations of protein, fat, and carbohydrate intakes with insomnia symptoms among middle-aged Japanese workers. J Epidemiol. 2013;23:132-138. doi:10.2188/jea.JE20120101

51. Lopresti AL, Hood SD, Drummond PD. A review of lifestyle factors that contribute to important pathways associated with major depression: diet, sleep and exercise. J Affect Disord. 2013;148:12-27. doi:10.1016/j.jad.2013.01.014
52. Rancillac A. Serotonin and sleep-promoting neurons. Oncotarget. 2016;7:78222-78223. doi:10.18632/oncotarget.13419

53. Inam QU, Haleem MA, Haleem DJ. Effects of long term consumption of sugar as part of meal on serotonin 1-a receptor dependent responses. Pak J Pharm Sci. 2006;19:94-98.

54. Banas SM, Rouch C, Kassis N, Markaki EM, Gerozissis K. A dietary fat excess alters metabolic and neuroendocrine responses before the onset of metabolic diseases. Cell Mol Neurobiol. 2009;29:157-168. doi:10.1007/s10571-008-9307-9

\section{Publish your work in this journal}

Nature and Science of Sleep is an international, peer-reviewed, open access journal covering all aspects of sleep science and sleep medicine, including the neurophysiology and functions of sleep, the genetics of sleep, sleep and society, biological rhythms, dreaming, sleep disorders and therapy, and strategies to optimize healthy sleep.
The manuscript management system is completely online and includes a very quick and fair peer-review system, which is all easy to use. Visit http://www.dovepress.com/testimonials.php to read real quotes from published authors. 